\title{
Assessment of Clinical Outcome of Patients With Primary Myelofibrosis Treated With Ruxolitinib in the Real-World Practice
}

\author{
Alaa Fadhil Alwan ${ }^{1}$, Yaseen Muhialdeen Taher $^{2} \&$ Hayder Adnan Fawzi ${ }^{3}$ \\ ${ }^{1}$ Department of Clinical Hematology, National center of hematology, Mustansiriyah University, Baghdad, Iraq \\ ${ }^{2}$ Department of Internal medicine, Hemato-oncology branch, Al-Iraqia University, Baghdad, Iraq \\ ${ }^{3}$ Department of Clinical Pharmacy, Baghdad Medical City, Baghdad, Iraq \\ Correspondence: Hayder Adnan Fawzi, Department of Clinical Pharmacy, Baghdad Medical City, Baghdad, Iraq. \\ E-mail: Hayder.adnan2010@gmail.com
}

Received: February 26, 2019 Accepted: April 26, 2019 Online Published: May 8, 2019

doi:10.5539/gjhs.v11n6p106 URL: https://doi.org/10.5539/gjhs.v11n6p106

\begin{abstract}
Background: Primary myelofibrosis (PMF) is a disease that characterized by bone marrow fibrosis which may result sometime in cytopenias and extramedullary hematopoiesis causing massive splenomegaly. Ruxolitinib (Rux) therapy that targeted Janus Kinase-2 receptor and approved for treatment of primary myelofibrosis.
\end{abstract}

Objective: Evaluate the clinical outcome of patients with primary myelofibrosis receiving Ruxolitinib treatment as a compassionate use program and compare this treatment with the best available treatment (BAT).

Methods: This is a retrospective case series conducted at the national center of hematology /Mustansiriyah University. The enrollment of patients started in May 2014 and ended in May 2017. There were 22 patients diagnosed with PMF ( 7 on the Ruxolitinib arm and 15 on best available treatment arm). The treatment response was evaluated according to consensus criteria of IWG-MRT 2013 in primary myelofibrosis.

Results: In this study 3 out of 7 patients on Ruxolitinib arm showed reduction in spleen size and reduction in anemia. In addition to that 4 patients showed clinical response specifically in spleen size (with $65 \%$ reduction from baseline during the first three months of treatment).

Conclusion: Rux is effective and safe to treating primary myelofibrosis with symptomatic splenomegaly.

Keywords: clinical outcome, primary myelofibrosis, ruxolitinib, real-world practice

\section{Introduction}

Primary Myelofibrosis (PMF) is a clonal proliferation of a hematopoietic stem cell caused by JAK2 mutation, MPL and calreticulin (CALR) genes. Clinical features of PMF differ widely range from asymptomatic to severe constitutional symptoms and massive splenomegaly (Cervantes et al., 2009; Mesa et al., 2007; Milosevic \& Kralovics, 2013). The clinical features of MF differ according to stage of disease (Cervantes, 2014).

The survival of patients with MF varied namely before 1995, the median survival was about 5 years (Cervantes et al., 2009). With improvement of best supportive therapy but before the era of JAK inhibitor therapy the median survival increased to 7 years. (Cervantes et al., 2012) stem cell transplantation offer cure for PMF but it can be offer for just minority of patients with MF, therefore for the majority of patients no curative therapy exists and the contemporary treatment consisted of controlling of disease symptoms like erythropoietin and hydroxyurea (Cervantes, 2014).

The dramatic change in treatment of MF has been shown after introduction of Ruxolitinib into the treatment of MF especially for symptomatic splenomegaly. Ruxolitinib is one of the JAK inhibitor approved for treatment of MF patients. The mechanism of action of this drug is primarily to inhibit dysregulated JAK-STAT signaling. Ruxolitinib has been shown to be very effective in decreasing spleen size and controlling the constitutional symptoms of MF especially fatigue, which in turn results in a marked improvement in the patients' quality of life (Verstovsek et al., 2010). The approval of Ruxolitinib was based on the results of randomized clinical trials of (COMFORT-I) and COMFORT-II (Verstovsek et al., 2012; Harrison et al., 2012). 
The effect of ruxolitinib is usually depended on its therapeutic continuity as there is strong evidence that splenomegaly will recur following discontinuation of drug which leads to reappearance of constitutional symptoms (Vannucchi et al., 2015). Furthermore, some patients on ruxolitinib will not achieve neither complete hematological response nor partial response, not to mention that bone marrow fibrosis is improved just in some patients who usually experience complete hematological response (Verstovsek et al., 2013). The aim of this study was to assess changes in spleen size and constitutional symptoms during Ruxolitinib treatment among patients with MF in real-world clinical settings.

\section{Subjective and Methods}

\subsection{Settings}

This is a single center study, retrospective case series study conducted at the national center of hematology in Baghdad. Seven patients with Primary MF treated with ruxolitinib part of)the compassionate use program) were enrolled in this study which started in May 2014 and end in May 2017. Those patients were compared with 15 patient with MF using best available therapy. The study was approved by review ethical committee of the national center of hematology center/Mustansiriyah University. All patients give their written inform consent prior to study.

\subsection{Study Objective}

The primary objective was to assess changes in spleen size and constitutional symptoms during Ruxolitinib treatment among patients with MF in real-world and to gain clinical experience on its use.

\subsection{Inclusion Criteria}

1) Patients aged $\geq 18$ years of age regardless of gender

2) No comorbidities

3) IPSS classification: high, intermediate (level 2 and 1) risk with an enlarged spleen

4) Established diagnosis with PMF, post PV-MF or post ET-MF, according to the 2008 World Health Organization criteria, irrespective of JAK2 mutation status

5) Good performance status ECOG score of $0,1,2$

\subsection{Exclusion Criteria}

1) Pregnant and lactating women

2) Patient with leucopenia ( $\mathrm{ANC}<1000)$ and platelet count $<100,000$

3) Hypersensitivity to JAK inhibitors or its excipients.

\subsection{Evaluation of Efficacy and Safety}

Continues surveillance of the patients for their complete blood count and spleen size. The data were collected from case report sheet of patients during their visit to the center. These data included general demographic data, laboratory investigation obtained at time of presentation and then every month for first 3 month then every 3 month thereafter.

\section{Results}

\subsection{Patients' Characteristics}

Age, gender distribution, type of MF, JAK2 mutation status, number of treatment lines offered, and laboratory analysis was similar between both groups, as illustrated in Table 1 . 
Table 1. Demographic and laboratory Characteristics of patients in both groups

\begin{tabular}{|c|c|c|}
\hline Characteristics & RUXO (n=7) & $\operatorname{BAT}(\mathrm{n}=15)$ \\
\hline Gender (Male to Female) & $3: 4$ & $7: 8$ \\
\hline Age (years), mean \pm SD & $57.5 \pm 6.32$ & $54.7 \pm 7.65$ \\
\hline Disease duration (years), median & 3 & 4 \\
\hline \multicolumn{3}{|l|}{ Type of MF } \\
\hline Primary MF & $5(71 \%)$ & $11(73 \%)$ \\
\hline Secondary MF (Post-PV) & $2(29 \%)$ & $4(27 \%)$ \\
\hline \multicolumn{3}{|l|}{ IPSS score } \\
\hline I & $0(0 \%)$ & $1(7 \%)$ \\
\hline II & $7(100 \%)$ & $13(86 \%)$ \\
\hline$>$ II & $0(0 \%)$ & $1(7 \%)$ \\
\hline \multicolumn{3}{|l|}{ JAK 2 status } \\
\hline Positive & $5(71 \%)$ & $6(40 \%)$ \\
\hline Negative & $2(29 \%)$ & $4(27 \%)$ \\
\hline Not done & $0(0 \%)$ & $5(33 \%)$ \\
\hline \multicolumn{3}{|l|}{ Number of treatment lines } \\
\hline $1-2$ lines & $2(29 \%)$ & $4(27 \%)$ \\
\hline $2-4$ lines & $4(57 \%)$ & $8(53 \%)$ \\
\hline$>4$ lines & $1(14 \%)$ & $3(20 \%)$ \\
\hline \multicolumn{3}{|l|}{ Laboratory features } \\
\hline Hemoglobin $(\mathrm{mg} / \mathrm{dl})$, median & 9 & 10 \\
\hline Patients with anemia $(<10 \mathrm{~g} / \mathrm{dl})$ & $4(57 \%)$ & $8(53 \%)$ \\
\hline WBC (cell x $\left.10^{9} / \mathrm{ml}\right)$, median & 7.4 & 8.3 \\
\hline Patients with leucocytosis $\left(>15 \times 10^{9}\right)$ & $2(29 \%)$ & $5(71 \%)$ \\
\hline Patients with leucopenia $\left(<4 \times 10^{9}\right)$ & $1(14 \%)$ & $3(20 \%)$ \\
\hline Platelet $\left(\right.$ cell $\left.\times 10^{9} / \mathrm{ml}\right)$, median & 174 & 194 \\
\hline Patients with thrombocytopenia $\left(<150 \times 10^{9}\right)$ & $1(14 \%)$ & $4(27 \%)$ \\
\hline Spleen size $(\mathrm{cm})$, median & 20 & 18 \\
\hline Patients with splenomegaly & $7(100 \%)$ & $15(100 \%)$ \\
\hline
\end{tabular}

SD: standard deviation, MS: myelofibrosis, PV: polycythemia Vera, WBC: white cell count, RUXO: ruxolitinib.

Of the 7 patients, 5 (71\%) started with $20 \mathrm{mg}$ twice daily of ruxolitinib, while $2(28 \%)$ patients started with $15 \mathrm{mg}$ twice daily the dose modifications based upon patients platelet and neutrophil status, but anemia was managed without dose reduction.

\subsection{Treatment Response}

Three out of the 7 patients showed clinical benefit in terms of reduction in splenic size and reduction in anemia, four patients have documented marked reduction in spleen size which was more obvious during the first 3 month of follow-up. In responsive patient on ruxolitinib use there was $65 \%$ reduction in spleen size.

\subsection{Adverse Events}

Adverse events due to ruxolitinib use were mild and easily manageable, so for hematological adverse event there were grade 2 anemias in 5 out of 7 patients and grade 2 thrombocytopenia in 2 out of 7 patients especially occurred during the $1^{\text {st }}$ three months of therapy. No patients suffered neutropenia (with or without fever), while non-hematologic $\mathrm{AE}$ there was just one patient (14\%) had gastrointestinal disorders and mild increase in liver 
enzymes occurred in one patient (14\%). All of the patients alive and in good health with no comorbidities, as illustrated in Table 2.

Table 2. Adverse events (AE) during treatment with ruxolitinib

\begin{tabular}{llllll}
\hline \multirow{2}{*}{ Parameters } & \multicolumn{3}{l}{ Grade of AE } & & \\
\cline { 2 - 6 } & I & II & III & IV & V \\
\hline Anemia & 2 & 5 & 0 & 0 & 0 \\
thrombocytopenia & 1 & 2 & 0 & 0 & 0 \\
Leucopenia & 0 & 1 & 0 & 0 & 0 \\
Gastrointestinal & 1 & 0 & 0 & 0 & 0 \\
Hepatobiliary disorders & 1 & 0 & 0 & 0 & 0 \\
\hline
\end{tabular}

\section{Discussion}

Primary myelofibrosis is part of myeloproliferative neoplasms (MPN). Around 50\% presented with JAK 2 gene mutation. The findings of the present study was in agreement with other studies; in which Rux offered reduction in spleen size, attenuation of constitutional symptoms of MF, and improvement of blood picture (hemoglobin, neutrophil, and platelet). This was in agreement with result of COMFORT-I trial, in this RCT Rux compared to placebo, Rux showed $41.9 \%$ reduction in spleen size compared to $0.7 \%$ for placebo $(65 \%$ reduction in the present study for Ruc and 15\% for BAT) (Verstovsek et al., 2010; Verstovsek et al., 2011).

The COMFORT-II trial designed to compare ruxolitinib therapy with BAT, in this RCT; $28 \%$ of the patients treated with Rux had 35\% spleen size reduction after one years of treatment while no patients on BAT had reduction in spleen size (Harrison et al., 2011)

In the current study anemia, ad thrombocytopenia were the most common AE, which is in agreement with both COMFORT I and II RCT ( $60 \%$ for CONFORT I). These hematologic toxicities may be explained by the mechanism of action of the drug, since JAK STAT pathway plays a central role in the signal transduction of erythropoietin and thrombopoietin, therefore its inhibition may result to anemia and thrombocytopenia (Parganas et al., 1998). In the current study, hematologic toxicities were mostly manageable. One common observation is that mild anemia and not thrombocytopenia were frequent in Iraqi patients received ruxolitinib at a dose of $20 \mathrm{mg}$ twice daily. Recognizing that there may be some biologic variability in Middle Eastern people which need large study to determine the optimal dose in this population merits investigation in future clinical trials. A limitation of the current study is the small sample size and non-probability sampling used.

\section{Conclusion}

Patients treated with ruxolitinib had a dramatic reduction in splenic size particularly evident within the $1^{\text {st }}$ three months of therapy in comparison to BAT. Thus, ruxolitinib is considered important treatment option for Intermediate- 2 to high risk myelofibrosis patients with massive splenomegaly. However, mild anemia and thrombocytopenia were common adverse events during the treatment and may be managed with blood transfusion, dose reductions or temporary discontinuation and/or use of erythropoiesis stimulating agents (ESA) and/or androgens.

\section{Acknowledgements}

The authors would like to thank Mustansiriyah University and the national center of hematology, for their support in the present work.

\section{Competing Interests Statement}

The authors declare that there are no competing or potential conflicts of interest.

\section{References}

Cervantes, F. (2014). How I treat myelofibrosis. Blood, 124, 2635-42. https://doi.org/10.1182/blood-2014-07-575373

Cervantes, F., Dupriez, B., Passamonti, F., Vannucchi, A. M., Morra, E., Reilly, J. T., ... \& Pereira, A. (2012). Improving survival trends in primary myelofibrosis: an international study. J Clin Oncol, 30, 2981-7. 
https://doi.org/10.1200/jco.2012.42.0240

Cervantes, F., Dupriez, B., Pereira, A., Passamonti, F., Reilly, J. T., Morra, E., ... \& Tefferi, A. (2009). New prognostic scoring system for primary myelofibrosis based on a study of the International Working Group for

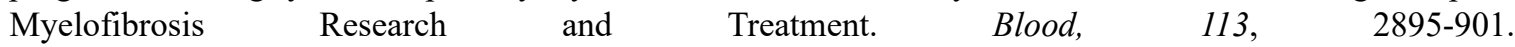
https://doi.org/10.1182/blood-2008-07-170449

Harrison, C., Kiladjian, J. J., Al-Ali, H. K., Gisslinger, H., Waltzman, R., Stalbovskaya, V., .. \& Barosi, G. (2012). JAK inhibition with ruxolitinib versus best available therapy for myelofibrosis. $N$ Engl J Med, 366, 787-98. https://doi.org/10.1056/NEJMoa1110556

Harrison, C. N., Kiladjian, J., Al-Ali, H. K., Gisslinger, H., Waltzman, R. J., Stalbovskaya, V., ... \& Barosi, G. (2011). Results of a randomized study of the JAK inhibitor ruxolitinib (INC424) versus best available therapy (BAT) in primary myelofibrosis (PMF), post-polycythemia vera-myelofibrosis (PPV-MF) or post-essential thrombocythemia-myelofibrosis (PET-MF). Journal of Clinical Oncology, 29, LBA6501-LBA6501. https://doi.org/10.1200/jco.2011.29.18_suppl.lba6501

Mesa, R. A., Verstovsek, S., Cervantes, F., Barosi, G., Reilly, J. T., Dupriez, B., ... Tefferi, A. (2007). Primary myelofibrosis (PMF), post polycythemia vera myelofibrosis (post-PV MF), post essential thrombocythemia myelofibrosis (post-ET MF), blast phase PMF (PMF-BP): Consensus on terminology by the international working group for myelofibrosis research and treatment (IWG-MRT). Leuk Res, 31, 737-40. https://doi.org/10.1016/j.leukres.2006.12.002

Milosevic, J. D., \& Kralovics, R. (2013). Genetic and epigenetic alterations of myeloproliferative disorders. Int J Hematol, 97, 183-97. https://doi.org/10.1007/s12185-012-1235-2

Parganas, E., Wang, D., Stravopodis, D., Topham, D. J., Marine, J. C., Teglund, S., .. \& Ihle, J. N. (1998). Jak2 is essential for signaling through a variety of cytokine receptors. Cell, 93, 385-95. https://doi.org/10.1016/S0092-8674(00)81167-8

Vannucchi, A. M., Kantarjian, H. M., Kiladjian, J. J., Gotlib, J., Cervantes, F., Mesa, R. A., ... \& Verstovsek, S. (2015). A pooled analysis of overall survival in COMFORT-I and COMFORT-II, 2 randomized phase III trials of ruxolitinib for the treatment of myelofibrosis. Haematologica, 100, 1139-45. https://doi.org/10.3324/haematol.2014.119545

Verstovsek, S., Kantarjian, H., Mesa, R. A., Pardanani, A. D., Cortes-Franco, J., Thomas, D. A., ... \& Tefferi, A. 2010. Safety and efficacy of INCB018424, a JAK1 and JAK2 inhibitor, in myelofibrosis. $N$ Engl J Med, 363, 1117-27. https://doi.org/10.1056/NEJMoa1002028

Verstovsek, S., Mesa, R. A., Gotlib, J., Levy, R. S., Gupta, V., Dipersio, J. F., .. \& Kantarjian, H. M. (2012). A double-blind, placebo-controlled trial of ruxolitinib for myelofibrosis. $N$ Engl $J$ Med, 366, 799-807. https://doi.org/10.1056/NEJMoa1110557

Verstovsek, S., Mesa, R. A., Gotlib, J., Levy, R. S., Gupta, V., Dipersio, J. F., ... \& Kantarjian, H. M. (2013). Efficacy, safety and survival with ruxolitinib in patients with myelofibrosis: results of a median 2-year follow-up of COMFORT-I. Haematologica, 98, 1865-71. https://doi.org/10.3324/haematol.2013.092155

Verstovsek, S., Mesa, R. A., Gotlib, J. R., Levy, R. S., Gupta, V., Dipersio, J. F., ... \& Investigators, O. B. O. A. C.-I. (2011). Results of COMFORT-I, a randomized double-blind phase III trial of JAK $1 / 2$ inhibitor INCB18424 (424) versus placebo (PB) for patients with myelofibrosis (MF). Journal of Clinical Oncology, 29, 6500-6500. https://doi.org/10.1200/jco.2011.29.15_suppl.6500

\section{Copyrights}

Copyright for this article is retained by the author(s), with first publication rights granted to the journal.

This is an open-access article distributed under the terms and conditions of the Creative Commons Attribution license (http://creativecommons.org/licenses/by/4.0/). 